\title{
PINTURA: EL VESTIGIO DEL CUERPO EN MOVIMIENTO
}

\author{
Painting: the vestige of the body in movement \\ Soledad Medina Cisternas \\ Pontificia Universidad Católica de Chile, Santiago, Chile \\ swmedina@uc.cl
}

\section{Resumen}

Aunque no lo tengamos en consideración cotidianamente, el origen de la pintura se remonta a manifestarnos los primeros actos comunicativos que poseemos de nuestros antepasados. Este hecho revela el poder que la manifestación del cuerpo ha podido otorgar al ser humano para que el acto expresivo corpóreo signifique el develar cierto mensaje. Para analizar este fenómeno, este artículo examina la obra del filósofo francés Maurice Merleau-Ponty, quien vuelve posible un estudio del acto pictórico ofreciendo una herramienta teórica sin precedentes desde su análisis fenomenológico de Lo visible y lo invisible. Con esto, el escudriñar la pintura primitiva significará adentrarnos en los poderes de la fenomenología para explicar el poder de la expresión pictórica desde sus inicios y cómo es posible entenderla como un vestigio incomparable en la relación entre cuerpo y mundo.

Palabras clave: arte, pintura, percepción, Merleau-Ponty, cuerpo, huella, acto pictórico.

\begin{abstract}
Although we do not have it in daily consideration, the origin of the painting goes back to manifest the first communicative acts that we have of our ancestors. This fact reveals the power that the manifestation of the body has been able to grant to the human being so that the corporeal expressive act means unveiling a certain message. To analyze this phenomenon, this article examines the work of the French philosopher Maurice Merleau-Ponty, who makes possible an analysis of the pictorial act offering a theoretical tool unprecedented from his in his phenomenological analysis of The Visible and the Invisible. With this, the scrutiny of primitive painting will mean entering to the powers of phenomenology to explain the power of pictorial expression from its beginnings and how it is possible to understand it as an incomparable vestige in the link between body and world.
\end{abstract}

Keywords: art, painting, perception, Merleau-Ponty, body, vestige, pictorial act.

Fecha de Recepción: 01/07/2019 - Fecha de Aceptación: 26/11/2019 
Desde la aparición de los primeros vestigios pictóricos en las cavernas, el cuerpo ha sido siempre un elemento imprescindible en la composición artística. De la manera que fuese, lo corpóreo se convirtió en la huella de la expresión comunicativa primera a través del gesto pictórico. El cuerpo estuvo allí presente en las representaciones desde la instancia en la que el sujeto se enfrentó a la posibilidad de dejar un vestigio. El vestigio de la expresión artística más antigua que tenemos de la humanidad corresponde al arte rupestre, pinturas caracterizadas por mostrar escenas de la vida cotidiana primitiva de los sujetos, partes del cuerpo humano, figuras, signos geométricos, escenas de caza de animales, entre otras cosas. La mayoría de estas pinturas rupestres dejan en evidencia la huella del hombre primitivo que, a través de sus manos, impregnó su marca en las paredes de las cuevas que rodeaban su hábitat. Así lo manifiesta Georges Bataille (2003) en su texto Lascaux o el nacimiento del arte: "Vemos en Lascaux una especie de ronda, de cabalgata animal, proseguida a lo largo de las paredes. Pero dicha animalidad es para nosotros el primer signo, el signo ciego, y por esto mismo el signo tangible de nuestra presencia en el universo" (18) refiriéndose a Lascaux, caverna primitiva encontrada en Francia llena de pinturas rupestres. Por consiguiente, la referencia que tenemos del origen de la manifestación pictórica del ser humano hace alusión a la marca, al vestigio que ha dejado el propio cuerpo físico en el mundo.

Por otro lado, en el siglo I d.C. Plinio el Viejo, escritor, científico, naturalista y militar latino, realizó estudios e investigaciones en fenómenos naturales, etnográficos y geográficos, recopilados en su obra Naturalis historia. En tal obra él cuenta un mito relacionado con el origen de la pintura:

\footnotetext{
Cabe señalar que, en aquella época, se desconocía la existencia de las pinturas rupestres. Cuenta Plinio que el amado de una muchacha de Corinto, hija de un alfarero llamado Butades, debía partir a un lugar lejano. En la víspera de su partida, la muchacha dibuja en una pared el contorno de la sombra de su amado, proyectada por la luz de una vela. Según este mito, la imagen se construye a partir de una sombra, no de la percepción directa de la realidad; es decir, dibujando el contorno. Un contorno que, según Plinio, da origen a la pintura. El dibujo que queda en la pared no es más que el cuerpo en negativo. Su ausencia (Feijóo 4).
}

La ausencia, en este caso, quiere hacer presente aquel cuerpo que no está, hace eterna la silueta de una figura como presencia. Con esto, el pensamiento de 'aquí estuvo alguien o algo' podría haber formado el propósito principal del inicio de la pintura. Curiosamente en este caso, tal como en el de las pinturas rupestres, nos estamos relacionando con el cuerpo humano, aunque ya no en el sentido de una 
marca directa de la propia representación del cuerpo, ahora nos referimos al juego que produce la marca ausente de este. De todas formas, ya sea en el caso del arte rupestre o en el del mito narrado por Plinio, la importancia del vestigio del cuerpo en el inicio de lo pictórico manifiesta la necesidad de dejar una huella, un signo tangible, como dice Bataille, que nos revela el nacimiento del devenir expresión corporal pictórica.

El cuerpo, esa vinculación, ese entrelazamiento viviente que tenemos con el mundo, se mueve sin descanso entre la experimentación fenoménica y apela ante ella en el hecho mismo de la expresión. La posibilidad de estudio sobre este movimiento, desde la pintura, nos apunta al desborde expresivo inevitable que ocurre desde lo psíquico y lo psicológico en el acto pictórico. Es decir, se evoca la cuestión del cuerpo más allá del ámbito biológico apelando inevitablemente al cuerpo incrustado en el mundo vivido, lo que finalmente posibilita la construcción teórica de la concepción expresiva en el sujeto. Todo esto nace en una atmósfera llena de energías primitivas en donde el juego entre presencia y ausencia del cuerpo como huella y vestigio se expone con suma importancia. Por consiguiente, podríamos reflexionar del siguiente modo: si, por un lado, la presencia inevitable de la corporalidad en la acción misma de pintar forja una base ineludible para comprender la construcción del arte en la vida de los seres humanos, entonces esto debe tener su propio peso en la práctica artística. Por lo tanto, ¿cómo comprobar y captar que aquella acción primitiva en su simplicidad fenoménica revela el gesto primero del hombre en tal acto expresivo, manifestando con esto que la pintura podría llegar a ser su propio vestigio corporal en su andar en el mundo? ¿Cómo la práctica artística puede volver a sus inicios y develar en lo pictórico toda aquella manifestación primitiva del hombre?

En las páginas venideras, trataremos de evidenciar la relevancia dentro de la historia de la pintura de este origen expresivo corporal enfatizando su importancia para la manifestación pictórica contemporánea. Tal análisis se verá enfocado desde un aporte teórico del filósofo fenomenólogo francés Maurice Merleau-Ponty. Este autor, en la última fase de su producción y en particular en la obra Lo visible y lo invisible, detalla la identificación de una dimensión del ser encarnada en nosotros, situada por debajo de nosotros, que nos lleva a pensar en una ontología indirecta. Tal ontología, por una transparencia originaria, descubriría una estructura inherente entre el sujeto, el mundo y el ser en la expresión primera del gesto corpóreo. El juego existente entre la dualidad de presencia-ausencia del cuerpo en la expresión pictórica apoyará también este análisis enfatizando la huella del movimiento gestual como un elemento clave. Este elemento funcionará en tanto se quiera conjugar la riqueza pictórica y la conexión entre el cuerpo físico y su fuerza expresiva, haciendo presente el fenómeno propio que evidencia de manera casi oculta el movimiento del cuerpo en el mundo. Así, la hipótesis que defiende el 
volver al momento primitivo de la expresión pictórica a través del cuerpo, intentará ser contrastada y validada sosteniendo la posibilidad de develar la manifestación de la propia existencia del ser humano en el mundo en tanto corporalidad. Esto, a través de la percepción visual, lograría ser atrapado y expresado como una marca del propio cuerpo que deviene presencia-ausencia pictórica.

\section{2.}

El cuerpo es aquí el elemento fundamental. Es la forma de probar la presencia física del hombre primitivo en la tierra. Behn y Wolfel (1967), historiadores del arte, lo narran así, identificando las primeras expresiones pictóricas del ser humano: "El cuerpo humano recorre todos los grados de la geometrización y va tomando significados convencionales. Nos hallamos aquí en presencia de una tentativa de escritura o, más bien, asistimos a su nacimiento" (24), analogando la escritura con las primeras expresiones pictóricas del ser humano debido a que se caracterizarían como formas de comunicación o de manifestación de su presencia en el mundo. Tras este origen, la pintura fue forjando un camino que, a través de la historia y del propio contexto político y social de la humanidad, evolucionó para expresar los recortes detenidos de la realidad presente de una forma cada vez más mimética. Así, por muchos siglos, se utilizó a la pintura como registro de la realidad que, en tanto técnica, evolucionó poco a poco cuando los sombreados y las luces pudieron revelar mejor aún los volúmenes y los planos de la imagen.

Sin embargo, desde la mitad del siglo XIX en adelante, la práctica artística como tal comenzó a variar y la irrupción del Impresionismo significó una nueva revolución pictórica que daría un pie de entrada a las vanguardias artísticas. Por primera vez se ponía en duda al ojo del pintor y se pasaba de querer generar un realismo total a la idea de mostrar simples manchas de la realidad que revelaban elementos como luces, sombras o colores que el pintor captaba y deseaba mostrar de los paisajes que le rodaban. El gesto pictórico que generaba el cuerpo del pintor impresionista según su ojo, es decir, su propia perspectiva del mundo alejada de la obsesión de la mímesis y el registro, volvía a aparecer. Con esto, el mismo cuerpo primitivo que se manifestaba en las cavernas volvía a revelar su importancia. El impresionismo vuelve a la idea de no perderse en los detalles que enmarcan la realidad, pretende develar aquello que marca la percepción del pintor y que, al poder ser manifestado en lo pictórico, le permite hacer presente su propia existencia perceptiva. Esto funciona de manera similar a como en algún momento el hombre primitivo manifestó su propia percepción de mundo en las cavernas: libre de toda tradición pictórica y con la sola intención de devenir expresión perceptiva en tanto vestigio corporal. 
Maurice Merleau-Ponty, escribe en base a esto en varios de sus textos enfatizando el rol y la importancia del pintor impresionista. El pintor vuelve al gesto primitivo en tanto se vale de la visión del cuerpo para obtener esta visión primaria, su mano vuelve a dejar una huella que deja el gesto pictórico con su pincelada. El pintor estaría dejándose conmover -moviéndose con el mundo- por todo aquello exterior que le afecta de alguna manera en su forma de percibir las cosas. Esto estaría totalmente conectado con una experiencia fenomenológica. Cito a Mearleau-Ponty desde El ojo y el espíritu:

[La pintura] da existencia visible a lo que la visión profana cree invisible, hace que no tengamos necesidad del 'sentido muscular' para tener la voluminosidad del mundo. Esta visión devorante, más allá de los 'hechos visibles', se abre a una textura del Ser cuyos mensajes sensoriales discretos no son más que las puntuaciones o las cesuras que el ojo habita, como el hombre su casa. Quedémonos en lo visible con su sentido estrecho y prosaico: el pintor, cualquiera sea, mientras pinta practica una teoría mágica de la visión (32).

Por consiguiente, todos los elementos propios del acto de pintar fueron ahora cuestionados y tanto el cuerpo, el material y las energías propias de la acción misma de pintar parecieron ser el centro de atención, cuestionamiento y experimentación. La obsesión que por siglos muchos de los pintores tenían con la mímesis para generar un registro de la realidad se vio liberada con la aparición de la fotografía y del registro fotográfico dando paso a la posibilidad de trabajar diversas cualidades de la pintura que se habían dejado de lado.

Así, nuevos movimientos pictóricos significaron una instancia esencial para volver a convivir con cierto automatismo, es decir, movimientos del cuerpo en acción, gestos de velocidad y energía traspasados al lienzo. Con este automatismo el artista tiene por finalidad expresar las pulsiones que surgen en su interior como fuerzas naturales: sería capaz de mostrar una realidad, una verdad desapercibida que, al parecer, el ser humano en su cotidianidad no lograría expresar de otra forma. Esto debido a que el material pictórico, en esta instancia, es capaz de reaccionar con cierta personalidad propia que, intensificada con el cuerpo mismo del artista, manifiesta una conexión con el mundo que pasa a ser expresada en la composición. Teniendo esto en claro, los artistas de las vanguardias iniciaron movimientos pictóricos como el Expresionismo, abriendo paso a lo contemporáneo. Aquí se extremaba la acción de entrega del pintor frente a un soporte donando su cuerpo de lleno en una creación desarrollada desde el instinto, desde las raíces de la consciencia activa, dejando de lado todo mecanismo técnico, toda figuración, toda tradición e historia pictórica. El ser humano comienza a volver así a lo rupestre. 
Andrea Giunta (2014) en su texto ¿Cuándo empieza el arte contemporáneo? Se refiere a la importancia de la respuesta que puede dar la contemporaneidad a ciertos sucesos perdidos u olvidados en la historia:

La inscripción de la contemporaneidad está continuamente enfrentada a lo irresuelto de la historia. El pasado se abre en el presente. [...] Retomar el pasado desde las imágenes del arte, analizar o poner en cuestión el estatuto de las iconografías gestadas como parte del imaginario de la nación, cuestionar sus valores, forma parte del repertorio del arte contemporáneo (25).

En este sentido, la pintura tomaría el poder de mostrar algo que ha quedado irresuelto, que aún queda por comprender y valorar, que bajo los ojos comunes y corrientes pasa desapercibido. Este fenómeno logra moldearse sobre un lienzo con lo pictórico: aparecen aquellas fuerzas invisibles que invaden los cuerpos y que son fundamentales como pulsiones para develar la conexión entre el mundo exterior y los cuerpos. Así lo logra demostrar, más contemporáneamente, el pintor Jackson Pollock a través del action painting, quien tomó la decisión de romper el bastidor que soportaba su lienzo y enfrentarse de mejor manera a la expresión pictórica:

En las imágenes que registran el proceso pictórico de Pollock, podemos observar cómo el artista destruye todas las barreras que distancian el cuerpo de la pintura. El cuerpo del artista entra en contacto con la obra y, formando parte del cuadro, lo rodea e incluso se adentra en él para dar lugar a un estrecho diálogo entre cuerpo y lienzo.

[...] La relación directa entre cuerpo y pintura que existía en tiempos prehistóricos, cuando el cuerpo ejercía de pincel, se pierde en la búsqueda de la representación fiel de la realidad, puesto que numerosos obstáculos se interpondrán entre el cuerpo del pintor y la pintura. Pero es con la adopción radical de Jackson Pollock, de colocar el lienzo en el suelo, donde el cuerpo y la pintura recuperan aquellos vínculos ancestrales (Feijóo 12).

En consecuencia, podemos evidenciar que perdida la necesidad de seguir parámetros establecidos para componer lo pictórico, el pintor en la contemporaneidad vuelve a acercarse a aquella vinculación primitiva que conectaba de manera ágil cuerpo y soporte. Lo pictórico ya no necesariamente debe volcarse en definir la historia de la pintura, sino que puede seguir tomando esa función expresiva de las pulsiones corporales del ser humano en el mundo vivido.

\section{3.}

El cuerpo, para Merleau-Ponty, es aquel punto crucial desde donde nuestra conciencia perceptiva nos vincula con el mundo. Esta fase de la obra merleaupontyiana puede ser identificada como un primer momento de su estudio donde se ve influenciado por la tradición fenomenológica que lo precede. El 
cuerpo constituye aquella base que dirige nuestra mirada hacia el mundo y, a la vez, se sitúa como la plataforma física que somos cuando el mundo nos interpela con su mirada. A partir de la herencia husserliana, dentro de la cual se enfoca en la cuestión del cuerpo, el filósofo francés trabaja una concepción de la corporalidad basándose en el movimiento fundamental del ser-del-mundo, tal como se indica en la Fenomenología de la percepción:

\footnotetext{
El cuerpo es el vehículo del ser-del-mundo, y poseer un cuerpo es para un viviente conectar con un medio definido, confundirse con ciertos proyectos y comprometerse continuamente con ellos. (...) Mi cuerpo es el quicio del mundo: sé que los objetos tienen varias caras porque podría repasarlas, podría darles la vuelta, y en este sentido tengo consciencia del mundo por medio de mi cuerpo (101).
}

Esta visión de cuerpo que plantea Merleau-Ponty desde la intervención del ser-delmundo para con el sujeto, muestra la unión psíquica-fisiológica que quiere desarrollar a través del suceso mismo de la percepción. Pero entendiendo al cuerpo como vehículo del ser-del-mundo se quiere también aquí deshacer de la visión clásica de dualidad alma-cuerpo y la relación objeto-sujeto; la irrupción merleaupontyiana frente a estas aristas llega a refutar la dualidad clásica existente frente a la comprensión de cuerpo y al rechazo de la psicología clásica por estar adjunta a tal dualidad, lo que abre la posibilidad de apoyo al trabajo de la psicología moderna. En este sentido, la obra merleaupontyiana es también capaz de alejarse del análisis de la tradición pictórica clásica y abre paso para analizar toda obra artística sujeta a las irrupciones vanguardistas que vienen a cuestionar la propia percepción del ser humano en el mundo y sus posibilidades.

Esta acción de aventurarse desde lo clásico hacia lo moderno hace alusión a una toma de conciencia global de la postura del ser humano en el mundo intersensorial, desarrollado a través del esquema corpóreo merleaupontyiano. Desde la espacialidad del propio cuerpo y su motricidad en torno a este espacio, se desarrolla la percepción de un esquema que apunta justamente al desarrollo del sujeto frente a la concepción de su cuerpo: se comprende una globalidad de lo que es cuerpo, es decir, un cuerpo unificado a través de la propia motricidad corpórea que surge en la espacialidad y que deviene acto expresivo. Este hecho, tras dos intentos de definición en su obra en torno a la articulación total del cuerpo - desde la funcionalidad corpórea aprendida por el niño hasta la funcionalidad de la conciencia global - recae en una tercera definición en donde la motricidad corpórea pasa a la acción de hacerse totalmente dependiente de su desenvolvimiento en el mundo, es decir, ya no se concibe al cuerpo en sí como prolongado desde y hacía a mí, se le concibe desde mí hacia el mundo.

Este entrelazado entre el cuerpo y el mundo para Merleau-Ponty será nombrado 'quiasma'. Es este entrecruzamiento que permite para él la formación de 
la chair, es decir, la 'carne' aquel exceso que para él supera al cuerpo mismo entendido como cuerpo propio-para explayarse en el mundo. La posibilidad del propio ser-del-mundo toma el carácter quiasmático para que el punto culmine entre el mundo y el cuerpo sea la carne, es decir, esta última será entendida como punto de indistinción entre sujeto y mundo. En el texto Lo visible y lo invisible Merleau-Ponty nos lo explica así: "Mi cuerpo modelo de las cosas y las cosas modelo de mi cuerpo: el cuerpo atado por todas las partes del mundo, pegado a él; todo eso significa: el mundo, la carne, no como hecho o suma de hechos, sino como lugar de una inscripción de verdad" (120), refiriéndose en exactitud a que aquél espacio que ocupa la carne significa una conexión imprescindible del sujeto con el mundo a través del cuerpo. Ahora bien, esta instancia de desarrollo con el mundo no hace más que volcarnos a percibir la acción expresiva del ser humano como una apertura desde el cuerpo hacia el mundo. Entender tal apertura resulta clave para los fines de este texto, es allí donde radica la importancia de la expresión pictórica del hombre primitivo haciendo presente su corporalidad. A la instancia de toma de posición del cuerpo en el mundo, Merleau-Ponty le llama 'gesto', un actuar comunicativo del cuerpo mismo, es la palabra misma salir del cuerpo. Con esto se quiere decir que el gesto constituiría la instancia inicial de toda comunicación siendo la modulación primera del cuerpo en un sentido semántico. Así, podríamos vincular a la palabra como la vestimenta que recubre al gesto o aquel recipiente vacío que de alguna manera lo contiene como conteniendo su verdadero sentido, sin atraparlo completamente. En la Fenomenología de la percepción lo explica así:

El sentido del gesto no está contenido en el gesto como fenómeno físico o fisiológico. El sentido del vocablo no está contenido en el vocablo como sonido. Pero forma la definición del cuerpo humano el que se apropie, en una serie indefinida de actos discontinuos, núcleos significativos que superan y transfiguran sus poderes naturales (210).

Al cuerpo, entonces, podemos relacionarlo directamente con el lenguaje; el lenguaje recae en el gesto, el cuerpo es gesto hacia el mundo y este gesto es la palabra hablante, a diferencia de lo que sería el signo, la palabra hablada. El desvío que ocurre en el gesto jamás logra ser atrapado por la palabra, sin embargo, el gesto se desarrolla en el cuerpo como una inmanencia que va más allá de propia palabra. Así, de alguna forma, el gesto pictórico que realiza el pintor, para Merleau-Ponty, escapa de la palabra y logra una apertura expresiva en donde el cuerpo y el mundo logran una instancia unificadora gracias al quiasma. Por consiguiente, el filósofo francés identifica que "no es con el objeto físico que puede compararse el cuerpo, sino más bien con la obra de arte [...] nudo de significaciones vivientes" (Merleau-Ponty, 1997 168) dejando en evidencia que la expresión artística en su gestualidad es capaz de hacer presente la propia corporalidad en su práctica. 


\section{4.}

Ahora bien, si lo expuesto anteriormente corresponde en general a comprender más una primera etapa de la obra de Merleau-Ponty, en una segunda fase podemos adentrarnos a sus teorías más personales. En este último Merleau-Ponty, que se puede identificar con su obra Lo visible y lo invisible, se manifiesta una fenomenología en la que nos invita a pensar en que justamente la obra de arte ofrece una apertura a un sentido que permanecería escondido bajo otras formas de expresión. Pero esta afirmación iría aún más allá que lo que se entendía en la Fenomenología de la percepción. En este sentido, la percepción sería el acceso originario al ser en donde la experiencia nos daría la inmanencia del sentido a lo sensible, comprobándose todo esto en la expresión misma. Así, tomamos por objetivo reflexionar en torno al sentido de un ser pre-objetivo que ha sido dejado atrás en gran manera por la ciencia y la reflexión filosófica, en un fenómeno de darse al mundo en su aparecer. Esto podría concluir en la experiencia pictórica como la expresión en tanto fenómeno que permitiría una inmanencia de sentido a lo sensible dentro de la concepción perceptiva en torno a la experiencia. ¿Por qué? La posibilidad de expresión del artista que se mueve en el terreno pictórico y que maneja el gesto en tanto corporalidad expresiva logra hacer inmanente un sentido a través de la propia expresión de la carne en su creación.

Así, la experiencia se torna el encuentro originario del ser con el mundo a través del cuerpo. Pero esta instancia no se debe pensar en tanto la revelación concreta de la verdad; la verdad fenomenológica implica la paradoja del aparecer del objeto como algo impresentable, esto es, la esencia de la cosa implica su donación en el curso de un flujo de escorzos. Estos escorzos, en tanto los entendemos como flujo de imágenes o recortes de la realidad, vienen a formar un aparecer que, como indica Merleau-Ponty, pueden manifestarse en la expresión pictórica con mayor libertad y posibilidad revelación de manera que: "la finalidad no es construir una señalización 'objetiva' del espectáculo [...] lo que se pretende es marcar sobre el papel una huella de nuestro contacto con ese objeto y ese espectáculo en cuanto que hacen vibrar nuestra mirada, virtualmente nuestro tacto, nuestros oídos" (Merleau- Ponty 2010 70). Por ende, la verdad fenomenológica que retoma y nos manifiesta Merleau-Ponty habita al sujeto encarnado en el mundo que, potencialmente, puede en la pintura explayar la experiencia de su propia encarnación o 'pintar en carne viva'. Como dirá luego Jean-Yves Mercury: "el acto de pintar es un intercambio y una alquimia de carnes" (2000 253).

Entonces, ¿cómo se presentaría el sentido que otorgaría el ser en esta dinámica? El ser se volvería visible a través de sus propios modos de aparecer, es decir, lo finito de nuestra fuerza perceptiva es un trazo constitutivo del ser. Así, la 
paradoja del aparecer da un vuelco en cómo se piensa la percepción para MerleauPonty, mostrando siempre una perspectiva humana corpórea de adecuación a los objetos del mundo. De esta manera, la misma presencia y la no-presencia de lo percibido devela un exceso de lo sensible que hace imposible poder reconducirlo a una trascendencia objetiva, por lo que Merleau-Ponty ocupará el concepto de invisible para explicar aquello que habita y posibilita lo sensible sin hacer presente lo sensible mismo. En este sentido, lo invisible se transforma en aquel reverso del exceso de lo visible que nos muestra una dimensión no constituida, negándonos poder percibir la realidad de cierta forma. Sin embargo, esta imposibilidad, esta negación perceptiva, es asumida por Merleau-Ponty como la condición aporética de la percepción para afirmar que esta falta es la condición absoluta para que los objetos puedan darse y ser pensados asumiendo una paradoja del aparecer y dando espacio a pensar la percepción como fuente originaria del conocimiento. Podemos entender entonces que la alteridad aquí se comprende desde una incompletud originaria en donde la cosa se manifiesta como ella misma, pero jamás en ella misma.

La percepción se constituiría como la inadecuación de principio de la donación de todo ente, situándose este pensamiento en los márgenes de la presencia con el fin de interrogar lo que nos es dado. Todo esto es posible gracias a la instancia de reversibilidad y de quiasma constituyendo una ramificación esencial del mundo en nosotros y de nosotros en el mundo. Así, el acto pictórico, para Merleau-Ponty, nos estaría enseñando a ver el mundo a través del reverso del exceso de lo visible. A través de la misma expresión de lo encarnado, el pintor develaría el flujo de sentidos que las cualidades mismas de la pintura -densidad, miscibilidad, volatilidad, dimensiones, formato, textura, absorción, forma, tamañopudiendo dar pie a la interacción misma del sujeto con el acto perceptivo de lo invisible. El artista, perdiendo el deseo de la figuración misma de los objetos es capaz de donar aquella interacción de escorzos que se relacionan entre sí en el mundo desde su propia visión de mundo, entregando aquel dato incalculable de la fuente originaria del conocimiento. La labor del artista sería entonces desarrollar la capacidad de llevar a la expresión el acto inmanente de la sensibilidad.

Sin embargo, ante todo lo dicho, la intención de este análisis es ir más allá que hablar de la pintura en general, es mostrar la relevancia del acto pictórico primitivo como instancia de toma de posición y de manifestación de libertad expresiva para el pintor. Allí, el ser humano aislado de toda tradición, de todo clasicismo pictórico, en la instancia misma de hacer presente su cuerpo en el mundo, es capaz de realizar una apertura mucho más valiosa que deviene pura inmanencia de sentido.

Aquel mito sobre la muchacha que expone la figura de su amado que citado en un principio como uno de los mitos iniciales de la pintura nos instala en la 
situación de que la ausencia del cuerpo devela la necesidad de marcar una huella previa a su ausencia. Este juego sería entonces quizá no de ausencia, sino más bien de no-presencia, marcando una instancia de presencia y no-presencia. He aquí la importancia de la impronta del cuerpo en la gestualidad primitiva pictórica: el vestigio, la huella del cuerpo que revela ese entrelazado evidente entre su propio ser y el mundo. La presencia y la no-presencia pasan a ser uno en la representación pictórica, lo que entabla un diálogo claro con la gestualidad propia del pintor. El contexto que se genera no se encuentra remitido al espacio de una interioridad clausurada sobre sí misma, sino que, al contrario, el sentido de ser de este ser humano se contrapone a una dimensión profunda que en él se manifiesta. De este modo, se abre el horizonte de un ser, en dicha dimensión, que pierde todo estatuto de positividad y de objetividad para venir a confundirse con el mismo movimiento de la experiencia que lo vuelve visible y lo posibilita. Allí se instaura el sujeto primitivo, que puede ya no situarse hace miles de años, puede estar aquí y ahora realizando la misma acción, pero correspondiendo a la libre disposición de su cuerpo pictórico expresivo.

De ahí que la percepción misma de esa expresión hecha por el pintor, remite a reconocer la alteridad de la propia gestualidad pictórica que se relaciona con el mundo y que hace visible la propia trascendencia del cuerpo en el mundo, que es el que logra esta misma percepción. Se va dejando de lado entonces toda tendencia a seguir patrones establecidos, a reproducir o representar, a aplicar pintura detenidamente sobre el lienzo: el cuerpo se transforma en puro devenir pictórico. Ronald Kay, teórico del arte contemporáneo, escribe en su texto Del espacio de acá en el capítulo "El cuerpo que mancha” lo siguiente:

\footnotetext{
Ya que la lengua, la letra, el cuadro y la foto exteriorizan el cuerpo y la mente humana y conforman las manifestaciones traspuestas, traducidas y trasladables del metabolismo social que ellas constituyen, se puede concluir que las secreciones orgánicas que se desprenden del cuerpo son la matriz anterior del lenguaje, los rudimentos somáticos de la imprenta y los balbuceos de la fotografía pero inmediatos, incontrolables, automáticos, reflejos, involuntarios, efectos del intercambio orgánico de la comunicación física del cuerpo con el universo natural. Las voces seminales, las letras fecales y los grafismos menstruales, pronuncian lo animal, imprimen lo invariable y expresan lo presocial, y en conjunto repiten, segundo a segundo, la ineludible sujeción del hombre al todo del cosmos y la innegable inclusión al tiempo y a la periodicidad de la naturaleza que antecede y excede a la historia. La mancha es la impronta húmeda, la letra primordial de dicha escritura corporal; es la huella inmediata que el organismo traza de su interior (30).
}

Exponiendo con esto que aquella informal e impensada composición que nace desde la mancha y el acto no figurativo desciende a dar a entender la propia movilización del cuerpo en el mundo y su apropiación. En este sentido, la composición del acto pictórico que trabaja aquella instancia primitiva, natural, 
comunicativa y pre-lingüística no es más que la propia valoración de la huella del cuerpo en el mundo que nace a partir de la impronta precaria. Así, la pintura resurge desde el automatismo primitivo y toma relevancia desde este punto como la marca del hombre en el mundo a través de su cuerpo gracias al acto perceptivo. Con esto, debemos asumir que aquella secreción propia del hombre en su aspecto orgánico biológico constituye incluso una instancia pictórica anterior a aquella pintura rupestre generada en una caverna. Esta instancia queda fuera de toda intencionalidad, pero hace presente el primer gesto que arroja el cuerpo en su andar y que lo hace partícipe de aquella dinámica entre presencia y no-presencia. El fenómeno de la mancha resulta ser la primera pintura, la primera comunicación: podemos pasar desde la secreción a la palabra, y debemos entender que este traspaso se hace presente por la corporalidad misma. Es en el acto pictórico primitivo en donde realmente el artista pinta en carne viva.

\section{5.}

Hoy en día el arte ha llegado, de muchas maneras, a potenciar la negación del poder pictórico en cuanto tal, al rechazo de usar la pintura para construir una obra. Esto aun cuando el ser humano con ello se encuentre frente a un soporte entregando su cuerpo de lleno en una creación desde el automatismo, desde las raíces de la consciencia activa, dejando de lado todo mecanismo técnico, toda figuración, toda tradición e historia pictórica. Si bien movimientos como el expresionismo abstracto y el informalismo desean volver a apropiarse de aquel fenómeno previo a toda composición pictórica intencional, es necesario que, aventurándonos en lo ya afirmado por Merleau-Ponty, extrememos aquellas medidas pictóricas que nos lleven a la expresión precaria y oculta que hoy en día nos revela los atisbos de la presencia misma del sujeto en el mundo. Cuestionar los pigmentos, cuestionar los soportes, cuestionar la herramienta de aplicación de lo pictórico puede otorgarnos conciencia de aquello que perdimos en el tiempo. Esto no con motivos nostálgicos, sino con la intención de apropiarnos de las herramientas que la creación pictórica nos entrega para la expresión misma del fenómeno perceptivo que nuestro cuerpo nos otorga. La pintura vuelve a nosotros como vestigio del cuerpo en movimiento, y ya no como pintura, quizá como secreción, quizá como mancha, sin forma, sin técnica. La pintura muestra que su infinita importancia no recae en su valor técnico, ni en su valor de registro, ni en su instancia de solemnidad dentro de las bellas artes, sino en la acción de develar aquella manifestación invisible que nos hace presentes y no-presentes a la vez en el mundo vivido.

La fenomenología, y específicamente en este caso la filosofía merleaupontyiana, vuelve posible un análisis potente del fenómeno pictórico ofreciéndole 
una herramienta teórica sin precedentes desde la fenomenología de Lo visible y lo invisible. Si volvemos al mito de Plinio y entendemos el juego de la sombra de la corporalidad, podemos entender que aquella dinámica entre presencia y nopresencia revela atisbos de la necesidad de entender el invisible que se manifiesta en la expresión pictórica que se genera desde el cuerpo. Esto, como dijimos en un comienzo en este artículo en tanto mera hipótesis, es posible a través del poder de la percepción visual, al lograr ser atrapado y expresado como una marca que deviene presencia y no-presencia corporal pictórica. Desde aquí, ya no hablaríamos de la pintura como la conocíamos, el acto pictórico llega a perder su tradición, su valor en tanto pintura de caballete. Para volver a otorgar sentido desde lo primitivo, se va en busca de lo recóndito sin necesitar de manera precisa de los implementos técnicos, solo hay cuerpo encarnado y su mancha en el mundo. Lo que resurge nace de un nihilismo positivo, de una negación que hace renacer una nueva construcción expresiva de la que el ser humano puede apropiarse para seguir develando su propia percepción del mundo.

\section{Bibliografía}

Bataille, George. Lascaux o el nacimiento del arte. Córdova: Alción Editora, 2003.

Behn, Friedrich. y Wölfel, Dominik. Historia del arte universal, Volumen I. Bilbao: Ediciones Moreton, 1967.

Feijóo, María de la Luz. "Cuerpo y pintura. Pollock: recuperación de vínculos ancestrales", Studies in Visual Arts and Communication an international journal 3/1 (2016): 1-12.

Giunta, Andrea. ¿Cuándo empieza el arte contemporáneo? Buenos Aires: Fundación ArteBA, 2014.

Mercury, Jean Yves. L'exressivité chez Merleau-Ponty. Du corps a la peinture. París: L'Harmattan, 2000

Merleau-Ponty, Maurice. El ojo y el espíritu. Buenos Aires: Paidós, 1977.

Merleau-Ponty, Maurice. La fenomenología de la percepción. Barcelona: Ediciones Península, 1997.

Merleau-Ponty, Maurice. Lo visible y lo invisible. Buenos Aires: Nueva Visión, 2010. Kay, Ronald. Del espacio de acá. Santiago Metales Pesados, 2005. 